\title{
Валентина Михайличенко
}

кандидат філософських наук, професор, кафедра педагогіки і психології управління соціальними системами ім. академіка I. А. Зязюна, Національний технічний університет «Харківський політехнічний інститут», Харків, Україна

ORCID: 0000-0001-7390-5319

E-mail:valentina_be@ukr.net

\section{Татьяна Гура}

кандидат педагогічних наук, професор, кафедра педагогіки і психології управління соціальними системами ім. академіка I. А. Зязюна, Національний технічний університет «Харківський політехнічний інститут», Харків, Україна

ORCID: 0000-0003-2323-3440

E-mail: tatyana-gura@ukr.net

\section{СПОСОБИ І МЕТОДИ ДІАГНОСТИКИ І РОЗКРИТТЯ ЛІДЕРСЬКОГО ПОТЕНЦИАЛУ СТУДЕНТІВ}

\begin{abstract}
Анотація: У статті приділено увагу актуальності розробки цілеспрямованої системи організації процесу діагностики, розкриття, активізаиії та розвитку лідерського потенціалу у студентів під час навчання у вузі. Вказано на необхідність усвідомлення студентами сутності лідерського потенціалу, знання якостей, щзо складають його основу, їх важливість в прочесі життєдіяльності. Розглянуто способи і методи виявлення студентів, які мають лідерський потенціал, на ранніх етапах їх навчання у вузі за допомогою спеціальних методик. Показана роль кураторів груп у виявленні лідерського потенціалу студентів. Вивчено фактори, які впливають на висунення студентів на позицію лідерів і роль групи в иьому процесі. Розглянуто форми позааудиторної діяльності студентів як необхідних умов для розвитку лідерського потенціалу. Показана роль студентського самоврядування у формуванні лідерського потениіалу та необхідність його активізації в сучасних умовах.

Ключові слова: лідерство, поняття, лідерський потенціал, лідерські якості, процес навчання, діагностика, виявлення, актуалізація, розвиток, студенти, способи, методи.
\end{abstract}

\section{Valentina Mikhailichenko, Tatyana Hura}

An extended abstract of a paper on the subject of:

"Ways and methods to diagnose and disclose leader potential in students"

Problem setting. In the article, there is accentuated the topicality of developing a purposeful system to organize the process of diagnostics, disclosing, activation, and development of leader potential in students during their study at a university. It is noted that solving this problem supposes a search and selection of efficient pedagogic technologies.
Recent research and publications analysis. In the process of analyzing the literature on this problem, there is offered a definition of leader potential. It is stressed that candidates selection for the role of leaders among students should be conducted by relying on not so much the actual, i.e.

(c) Валентина Михайличенко, Татьяна Гура, 2019 
developed and observed traits, but on potential abilities and predisposition to leadership.

Paper main body. There is shown the necessity of students' realizing the essence of leadership potential, the presence of traits composing its basis, their significance in the course of a person's life. Self-consciousness formation in students supposes realization of expedient methods, modes, and means in the form of recommendations offered by the authors. There have been viewed the ways and methods to detect students possessing leadership potential at early stages of their studying at a university. The role of diagnostics through special methodologies is shown, as well as the role of training. There have been studied the factors that influence students' being put forward for leading positions and the role of the group in this process. There have been viewed the ways to involve students in a leader's activity in purposefully organized cognitive-professional situations, as well as in a modelled situation, or a game. To create situations wherein a personality can learn to perform a leader's behavior, it is recommended to apply plot-androle games, trainings, case-methods, and other interactive teaching technologies. The role of modelling in this process is shown as well as that of tutors. It is accentuated that favorable possibilities for disclosure and activating leadership potential in students are created by pedagogues in the environment of cooperation relationships and partnership with students. The result of personality-oriented interaction established between students and lecturers is formation of imitativeness, interest in common activities results, co-ordination of actions, establishment of trust, mutual understanding,

Постановка проблемы в общем виде и её связь с важными научными или практическими заданиями. Высшая техническая школа должна обеспечить подготовку специалистов-лидеров, проявляющих социальную активность, организаторские навыки, готовых к joy and success experience, which activates the learning process.

There is accentuated the need in forming self-organizing abilities, which is enhanced by students' extracurricular work that permits the greatest range of activities for such a process. This facilitates selfanalysis, self-evaluation of work results, orientating at a personality's selfimprovement. There has been shown the role of students' self-government in leadership potential formation and the need of its activating in modern conditions as a form of students' self-organization, a mechanism of representation and defending of their rights and interests, a possibility of self-realization. This enables to conclude that students' selfgoverning may be viewed not only as a students' practical activity and a form of educative work at a university, but also as one of youth policies form directed at the use of students' leadership potential in socioeconomic life of the country to the fullest.

Conclusions of the research. As a result, the conclusion is made that at present, there is a tendency to adapt to modern conditions long since known forms of students' life organizing along with development new ways and methods, and students' needs with stimuli to develop their social activity are detected. There is noted the need for the mentioned tendencies being realized within a university's education environment together with the forms and mechanisms of work with students, and interaction of the training and extracurricular processes lead in total to solving a significant social task - training initiative, independent, responsible leaders capable of efficient managerial activity in modern conditions of social development.

эффективному руководству другими людьми, направленному на достижение поставленных перед ними целей. Для этого в рамках учебно-воспитательного процесса необходимо создание эффективных педагогических условий. Именно во время обучения в заведении 


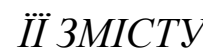

$\begin{array}{lcr}\text { высшего } & \text { образование } & \text { у студентов } \\ \text { наиболее } & \text { полно } & \text { проявляются }\end{array}$

организаторские склонности, лидерские качества, необходимые для эффективного руководства другими людьми, а также формируются и развиваются умения и навыки лидера. Поэтому следует разработать целенаправленную систему организации процесса диагностики, раскрытия, активизации и развития лидерского потенциала студентов. Решение данной проблемы предполагает поиск и выбор эффективных педагогических технологий.

Анализ последних исследований и публикаций позволяет утверждать, что потенциал личности следует рассматривать как систему природно-обусловленных и возобновляющихся ресурсов, реализация которых в течение жизни приводит к определенным, с точки зрения личности и общества, значимым личностным достижениям [6, с.89]. Понятие «лидерский потенциал» является разновидностью более общей категории «потенциал личности» и представляет собой диалектическое единство явных и непроявленных ресурсов. Лидерский потенциал в обобщенном виде рассматривается как возможность и готовность индивида к эффективному лидерскому поведению [3]. Это системная характеристика личности, в связи с этим её психолого-педагогическая сущность является предметом изучения со стороны разных ученых.

Изучению лидерского потенциала посвящены работы Н. Беляковой. Б. Головешко, А.Зориной, И. Дрыгиной, О. Евтихова, С. Калашниковой, А. Кныш, И. Костыря, А.Романовского и др. А. Г.Романовский, В. Е. Михайличенко на основе результатов многочисленных исследований разних авторов по проблеме лидерства дают такое определение лидерского потенциала: Это совокупность всех компонентов структуры личности (личностнорефлексивный, познавательно-профес- сиональный, ценнностно-мотивационный, организачионно-управленческий, эмоцииональный, коммуникативный), которые обеспечивают её эфффективное влияние на членов группь при совместном решении задач в различных ситуациях [6, с.90-91]. Многие исследователи придерживаются позиции, что поскольку лидерство не может быть сведено к набору личностных качеств или способностей, данных человеку от природы, а является особым видом межсубъектных отношений, то соответственно потенциал лидера в определенной степени можно развивать, а лидерству можно обучаться. Дж. Адаир делает вывод о том, что лидерство может развиваться путем обучения, что лидерами становятся. Личность лидера можно сформировать в соответствующей образовательно-профессиональной среде, создав для этого благоприятные условия $[1, \mathrm{c} .6]$.

Так как выдвижение лидера осуществляется в процессе деятельности, то через специально организованную работу в группах можно обеспечить ситуации, направленные на создание благоприятных возможностей для успешного становления в качестве лидеров студентов, обладающих лидерским потенциалом. Исследование социально-психологических

особенностей проявления лидерства в студенческих группах проводилось $\mathrm{H}$. Беляковой. При рассмотрении взаимодействия «лидер - группа» автор акцентировала внимание на втором слагаемом - «группе», подчеркивая, что именно цели и мотивы группы обуславливают обстоятельства возникновения лидерства. При этом принятые группой лидеры, благодаря своей центральной позиции, играют важную роль в формировании и изменении групповых целей, мировоззрения, а также в организации структуры и совместной деятельности членов группы [2, с.16]. 
Формулирование целей статьи

(постановка задач). Цель статьи состоит в обобщении известных способов и методов диагностики и раскрытия лидерского потенциала на ранних стадиях процесса обучения, систематизации действующих и поиске новых инновационных технологий его активизации и развития.

Выделение нерешенных ранее аспектов общей проблемы заключается в том, что до сих пор нет четкого определения понятия «лидерский потенциал» и его содержания. Это затрудняет разработку целенаправленной системы организации процесса его диагностики, раскрытия, активизации и развития.

Изложение основного материала исследования с полным обоснованием полученных научных результатов. Решение поставленной проблемы связано с педагогическим обеспечением совершенствования методов, средств и организационных форм, обеспечивающих выявление лидерского потенциала, его активизацию и развитие. При этом выявление необходимо осуществлять, опираясь не столько на актуальные, то есть развитые качества, сколько на потенциальные способности и склонность к лидерству, что требует не только диагностики лидерского потенциала, но и мобилизации ресурсных возможностей студентов в проявлении лидерских способностей во время обучения в зво.

В процессе самоопределения студентам необходимо понять сущность лидерского потенциала, знать качества, умения и навыки, составляющие его основу, и осознать их важность в процессе жизнедеятельности человека. Этому способствует обсуждение со студентами проблемы становления личности, знакомство с понятием «лидерский потенциал» как интегративной характеристики личности, его значимость в процессе жизнедеятельности человека. Последовательное ценностное осмыс- ление лидерского потенциала предусматривает формирование самосознания студентов, способствующего пониманию ими собственных лидерских потребностей и возможностей, что является необходимым условием и начальным этапом работы по его раскрытию и активизации. Самоопределению студентов будет способствовать организация образовательного модуля «Лидерство» по курсу «Введение в специальность», организации встреч с лидерами, достигшими значительных результатов в своей деятельности, что предполагает участие студентов в проблемных диалогах, дискуссиях, беседах.

C точки зрения педагогического сопровождения, формирование самосознания студентов предполагает реализацию целесообразных методов, приемов и средств ознакомительного, рекомендательного характера. Предметом обсуждения являются личностные смыслы отношения студентов к жизни, самому себе, область их проявления в процессе жизнедеятельности. Уровень осознания студентами значимости лидерства повышается благодаря увеличению информации о лидерстве, обсуждению различных точек зрения о способах поведения лидера, стилях руководства и других аспектах его деятельности.

Выявление студентов, обладающих лидерскими качествами, должно начинаться с первого года обучения, проводиться преимущественно на уровне академических групп и осуществляться, прежде всего, преподавателямикураторами, которые раньше всех других имеют возможность близко познако-миться со студентами и оценить их потенциал. При этом должен быть учтен опыт участия студентов в общественной работе, полученный ещё в школе, а также результаты собственного наблюдения их активности. И хотя далеко не все студенты, активно занимающиеся общественной работой, впоследствии становятся 
эффективными лидерами, именно у них имеется больше шансов для реализации себя в данной области. Проблема заключается в том, что многие студенты начальных курсов не чувствуют пока своего лидерского потенциала или не видят способов и методов его проявления в студенчиской жизни. Но среди них выделяются социально активные студенты, для которых характерно заинтересованное отношение к окружающему, желание влиять на происходящие процессы, стремление к лидирующим позициям.

Выявлению студентов, обладающих лидерскими качествами, на ранних этапах их обучения в вузе, способствует проведение комплекс конкурсных творческих работ. По мнению Н. Кирюшиной, Е. Тихоновой, это смотр студенческой самодеятельности, конкур-сы стенгазет по различным тематикам, литературные конкурсы, спартакиады и другие. Участие в их подготовке и реализации позволяет студентам эффективно пройти процесс адаптации к вузовской среде, активно включиться в систему межличностного взаимодействия, а студентам-лидерам - проявить свои организаторские качества. При этом первокурсникам необходимую методическую помощь могут оказать студенты старших курсов, исполняющие роль наставников и проводников мероприятий, способствующих включению в совместную деятельность [4, с.30].

Выдвижению в позицию лидеров способствует целенаправленное формирование актива студенческой группы, что является первоочередной задачей кураторов, а также наблюдение за действиями предполагаемого лидера, его процессуальными и структурными изменениями. Для этого необходимо создание ситуаций реального взаимодействия студентов в значимой для группы сфере жизнедеятельности. Наблюдение за группой и происходящими в ней процессами может осуществляться в реальной ситуации, а также в смоделированной ситуации, игре. Для осуществления такой деятельности кураторов необходимо обеспечить дидактической базой, которая должна включать, прежде всего, методические рекомендации по осуществлению учебной и внеучебной работы со студентами младших курсов, разработанные в соответствии с основными нормативными документами, дополненные собственным творческим подходом педагога.

Поведение преподавателей и кураторов студенческих коллективов, которые в большей или меньшей степени осуществляют организаторскую деятельность в группах, во многом становится примером для подражания. Действующие в группе лидеры во многом копируют поведение преподавателя - то, как он общается со студентами, какими методами и средствами он стремится добиться их расположения и выполнения поставленной им задачи. Поэтому очень важно для преподавателей занять позицию партнера, советчика, друга, благодаря чему в коллективе устанавливается эмоционально-положи-тельная атмосфера, благоприятная для дальнейшего развития инициативности и активности студентов в организаторской деятельности.

Одним из главных факторов, которые мешают формированию лидерского потенциала, является недостаточное знание и понимание самого себя, своих качеств, способностей, интересов. Без этого невозможно ни профессиональное становление, ни проявление себя как лидера. Цель обучения - помочь будущему специалисту познать свой внутренний мир, своё предназначение и самоценность, стимулировать стремление к самосовершенствованию. Этот процесс предполагает наполнение его личностным смыслом, который зависит от потребностей, ценностей, мотивов и убеждений студентов. 
С целью выявления лидерского потенциала следует проводить с помощью специальных методик исследования диагностику наличия психологических особенностей лидер-ства. Важная роль в процессе выявления лидеров должна быть отведена тестированию. Наиболее часто исполь-зуют следующие тесты: диагностика лидерских способностей, предложенная Е. Жариковым, Е. Крушельницким, определение уровня лидерского потенциала, диагностика функцио-нального лидерства в малых группах, самооценка лидерства и др. Для оценки лидерского потенциала студентов предлагается использовать в тестах вопросы, затрагивающие основные стороны жизнедеятельности студенческой группы - учебную, профессиональную, научную, общественную, эмоциональноличностную.

Используемые для выявления лидеров тесты должны быть комплексными, ориентированными на раскрытие мотивации и направленности студентов, их склонностей и интересов, коммуникативных, организаторских способностей. Следует иметь представление о сущностных характеристиках личности, необходимых для становления студента как лидера. В разработке тестов и обработке их результатов должны принимать участие специалисты - психологи и социологи. Эффективность тестовых методик подтверждается их широким применением в зво. Они достаточно часто используется также в частных и государственных компаниях для выявления лиц, способных к эффективному управлению.

Хорошим дополнением к тестовым опросам является использование тренинга в целях диагностики. В психологическом тренинге наглядно проявляются особенности взаимоотношений между членами коллектива, а также способности студентов действовать определенным образом в моделируемых ситуациях. При этом участников тренинга следует предупреждать о его диагностических целях и о степени конфиденциальности результатов диагностики. В противном случае будут нарушены важные этические принципы психологического тренинга, необходимые для формирования доверительных отношений в группе и создания атмосферы, способствующей самораскрытию участников.

Одним из методов діагностического подхода является метод референтнометрии, который применяется для выявления групп и лиц, обладающих ценностной значимостью для других людей, к мнению которых студенты прислушиваются, хотя в своем поведении не всегда на него ориентируются. Этому способствует привлечение студентов к деятельности лидера в специально организованных познавательно-профессиональных ситуациях. Образовательная стратегия приобщения должна быть направлена как на овладение студентами известными способами выполнения совместной деятельности, так и на выработку ими собственных и целесообразных методов и средств взаимодействия. При этом они должны быть ориентированы на завоевание авторитета и доминирование в группе, чтобы студенты почувствовали свои потенциальные лидерские возможности и, попытавшись их реализовать, приобрели некоторый организационно-управленческий опыт. Для создания ситуаций, в которых личность может учиться осуществлять поведение лидера применяют сюжетно-ролевые и деловые игры, тренинги, кейс-методы и другие интерактивные технологии обучения.

Выявление уровня развития лидерского потенциала студентов осуществляется также в ходе выполнения ими психологических тренингов. Здесь необходима точность моделирования профессиональной ситуации и отработанность процедуры фиксирования результатов деятельности. Практическую деятельность в моделируемых ситуациях называют тренировкой, в результате 
которой происходит приобретение опыта, который становится важным и необходимым для формирования умений и навыков эффективного лидера. Как отмечает С. Макшанов, именно возможность работы непосредственно с опытом позволяет использовать психологический тренинг в качестве важного элемента профессиональной подготовки. По его мнению «в традиционных формах профессиональной подготовки студент вначале получает информацию, и только через неопределенное время имеет возможность ее использовать. Только тогда происходит реальная оценка субъектом возможности применения полученного знания и его частичное закрепление. В тренинге, напротив, создается возможность незамедлительного соотнесения полученной информации и актуальной деятельности. Тренинг помогает преодолеть ограничения, накладываемые на профессиональную деятельность традиционными методами обучения, и способствует приобретению эффективных практических навыков работы» [5, c. 204-206].

Проявления

лидерских

характеристик у студентов должны активно поддерживаться педагогом в процессе совместной деятельности и общения в процессе подготовки и проведения групповых, факультетских и вузовских мероприятий, студенческих научно-практических конференций и других мероприятий, связанных с публичной самопрезентацией. Они помогают потенциальному лидеру учиться эффективному общению с другими людьми, способности говорить убедительно и аргументированно, умению слушать и отвечать на вопросы, самопрезентовать себя. В процессе проводимой работы повышается уровень самооценки студентов, появляется уверенность в себе, повышается их самоэффективность.
Создавая ситуации сотрудничества

и партнерства со студентами, преподаватель стимулирует активность студентов, их стремление к самостоятельному творческому поиску, личностному росту, раскрытию и активизации лидерского потенциала. Благоприятные возможности для этого создаются при условии принятия преподавателем личности каждого студента как неповторимой индивидуальности, имеющей собствен-ные интересы, потребности, взгляды, личностные ценности и стремящейся к саморазвитию и самореализации. Создание отношений доверия и взаимопонимания между преподава-телями и студентами способствует переживанию радости и успеха активи-зирует процесс обучения.

Задача педагога состоит в том, чтобы создать условия и обогатить опыт самого студента и научиться оценивать опыт других. Студенту необходимо выработать собственные средства, методы приобретения лидерского опыта, обеспечивающего ему успешную профессиональную деятельность. При этом полезно проживание ситуаций достижения успеха, в которых студенты получают удовлетворение и эмоциональное подкрепление. Такое состояние способствует личностному росту обучающихся, а также даёт возможность реалиизовать одну из главных задач учебновоспитательного процесса - осознать свои возможности и поверить в себя.

Для репетиции уверенного поведения используются ролевые игры, моделирующие ситуации, которые в свое время создали или могут создать определенные сложности для участников. При этом преподаватель выступает в роли тренера, а игра строится на основе взаимодействия одного из членов группы c другими участниками, которые представляют значимых для него лиц. Преподаватель обычно начинает с таких банальных ситуаций, которые могут 
создавать трудности для большинства неуверенных в себе людей, как необходимость обратиться с просьбой, ответить отказом. Примером может стать тренировка различных коммуникационных навыков, включая внимание к собеседнику, способность к самораскрытию в разговоре, умение делать и принимать комплименты, менять тему разговора, начинать и заканчивать разговор, выдерживать паузы.

Отработка поведения в группах тренинга умений основана на следующих принципах. Во-первых, преподаватель или какой-либо ее участник может моделировать «правильное» поведение в разыгрываемых на занятиях ситуациях. Моделирование - это особый прием поведенческой реакции, использование которой весьма эффективно в случаях, когда членам группы требуется освоить новые или усилить недостаточно выраженные формы поведения. Вовторых, члены группы осваивают новый для них способ поведения, наблюдая за тем, как его моделируют другие участники или преподаватель, а также за своими реакциями на моделируемое поведение. В некоторых группах применяют аудио- и видеозаписи моделей образцового поведения. Моделирование полезно, когда участники имеют очень слабое представление о том, как надо действовать в данной ситуации, чтобы их поведение было уверенным. Группы, состоящие из более опытных участников, могут сразу переходить к репетиции поведения. Разыгрывая различные роли, члены группы вовлекаются в групповой процесс и приобретают новые полезные поведенческие навыки.

Еще одним компонентом процесса
отработки поведения подкрепление. Подкрепление - это поощрение или любая позитивная реакция со стороны преподавателя или членов группы. Очень важно, чтобы подкреплялось любое, даже самое небольшое достижение по мере того, как отрабатываемая реакция постепенно приближается к оптимальной. Подкрепление обычно применяется, чтобы формировать поведение отдельных участников на достижение тех целей, которые они сами перед собой ставят. Результатом личностно-ориентированного взаимодействия, установившегося между студентами и преподавателями, является формирование инициативности студентов, заинтересованности в результатах совместной деятельности, согласованность действий, возникновение доверия, взаимной поддержки, взаимо-понимания.

Представляет интерес опыт подготовки лидеров в «Центре лидерства» кафедры педагогики и психологии управления социальными системами им. акад. И.А. Зязюна Национального технического университета «Харьковский политехнический институт» при участии её профессорско-преподавательского

состава под руководством профессора А.Г. Романовского [8, С. 98-100]. Кафедра является с 2015 года участником международного Проекта «ЕLITE» «Образование для лидерства, интеллигентности и развития таланта» в рамках программы TEMPUS. В процессе реализации данного проекта, признанного успешным представителями научных школ Украины, профессорско-преподавательский состав кафедры не только принял самое активное участие в реализации его программных задач, но и заложил основы формирования Харьковской школы лидерства.

Важным направлением в деятельности Центра лидерства в первый год его существования стало внедрение в учебный процесс системы тренингов для развития лидерского потенциала старост групп кафедры. Интересной и действенной формой также является кураторская (вожатская) деятельность студентов старших курсов в отношении студентов младших курсов. Одновременно с практическим функционированием в качестве лидеров, что актуально для студентов-старшекурсников, этот вид деятельности решает важную задачу адаптации студентов-первокурсников к условиям вузовской среды.

Система обучения лидеров включает также воспитание способностей к 
самоорганизации, самодисциплине, самоанализу, самооценке результатов деятельности, ориентацию на самосовершенствование личности. Благоприятные возможности создает организация различных внеаудиторных форм обучения в рамках мероприятий в различных сферах студенческой жизни. Такая деятельность предполагает гармоничное сочетание обучения лидеров и самовоспитания путем самоорганизации. Внеаудиторная работа создает возможность использовать наибольшую вариативность такого про-цесса, когда студенты могут активно включаться в неё и приобретать лидерский опыт.

Большую роль в этом процессе играет студенческое самоуправление как форма самоорганизации студентов, механизм представительства и отстаивания своих прав и интересов, возможность самореализации, что, в свою очередь, является необходимым инструментом развития лидерского потенциала в современном университете. Одновременно студенческое самоуправление можно рассматривать как проявление демократической организации и автономии университета, как процесс и результат выбора студенческим сообществом своих позиций, целей и способов их достижения [9, с. 149]. Вместе с тем соотношение феномена «лидерства» и «студенческого самоуправления» заслуживает рассмотрения в рамках отдельного направления для научного поиска.

Сегодня в Украине студенческое самоуправление признается неотъемлемой частью гражданского самоуправления в заведениях высшего образования. Деятельность органов студенческого самоуправления упорядочена законодательством, статусом университета и положением о студенческом самоуправлении. Каждое заведение имеет право определить, в зависимости от собственной специфики, оптимальные формы и уровни студенческого самоуправления, в рамках которого студе- нты имеют право решать вопросы обучения и отдыха, защищать собственные права и интересы, а также брать участие в управлении вузом через выборные органы самоуправления.

По результатам исследования, проведенного Л. Червоной, выделены следующие тенденции в развитии студенческого самоуправления, которые прослеживаются в украинских заведениях высшего образования [9, С.154].

$1.68 \%$ украинских студентов не владеют информацией относительно того, что представляет собой студенческое самоуправление, какие его органы действуют в их заведениях, какими документами регулируется его деятельность в ЗВО, какие основные задачи оно решает.
2. Параллельно
существуют традиционные профсоюзные студенческие организации и органы студенческого самоуправления рассматриваются большинством студентов как равнозначные, что говорит о нечетком представлении студентов об их роли и задачах по защите их прав и интересов.

3. Довольно низкая активность участия студентов в деятельности органов студенческого самоуправления. При этом $50 \%$ студентов считают, что благодаря студенческому самоуправлению они могут развивать свой личностный потенциал лидера, а $54 \%$ считают, что эти органы реализуют гражданские права студентов и формируют у них чувство ответственности [9, C.154].

Актуальность развития студенческого самоуправления подтверждается вниманием со стороны не только вузовской общественности, но и органов государственной власти. Это позволяет сделать вывод о том, что студенческое самоуправление можно рассматривать не только как практическую деятельность студентов и форму воспитательной работы в образовательном учреждении, но и как одну из форм молодежной политики, 
направленной на наиболее полное использование лидерского потенциала студенчества в социально- экономической жизни страны.

Выводы из данного исследования и перспективы дальнейшего изучения данного направения. Таким образом, в настоящее время адаптируются к современным условиям давно известные формы организации студенческой жизнедеятельности, разрабатываются новые способы и методы, выявляются потребности студентов и стимулы развития их социальной активности. В связи с этим необходимо повышение квалификации кураторов и преподавателей, для которых должен быть организован цикл научнометодических семинаров по различным проблемам обучения лидеров, включая проблемы, связанные с диагностикой лидерского потенциала, его выявлением и

\section{Список літератури}

1. Адаир, Дж. (2007) Психология лидерства. М.: Эксмо, 352 с.

2. Белякова, Н. В. (2002) Социальнопсихологические особенности проявления лидерства в студенческих группах: дис. канд. психол. наук: 19.00.05. М.,197 с.

3.Гура, Т. (2015) Лідерський потенціал як важлива складова педагогічної культури викладача технічного університету. Педагогіка формування творчої особистості у вищій i загальноосвітній школах: зб. наук. пр. Редкол.: Т. І. Сущенко. Вип. 44 (97). Запоріжжя: КПУ. С. $418-428$.

4. Кирюшина, Н. Ю. \& Тихонова, Е.Л. (2010) Система подготовки лидеров в университете. Вестник Нижегородского университета им. Н. И. Лобачевского. С. $27-33$.

5. Макшанов, С. И. (1997) Психология тренинга: теория, методо-

\section{References}

1. Adair, Dzh. (2007) Psihologija liderstva. [Leadership Psychology]. M.: Jeksmo. 352 p. [in Russian] формированием. Цель педагогических семинаров - вооружение преподавателей и кураторов знаниями, необходимыми для работы со студентами-лидерами, а также методами и средствами его активизации; а также осознание необходимости выстраивания отношений со студентами на принципах личностно-ориентиро-ванного взаимодействия.

В дальнейшем следует провести специальные исследования, связанные с изучением эффективности способов и методов работы со студентами, реализуемых в образовательном пространстве зво по подготовке лидеров. Самоуправление же необходимо рассматривать не только как инициа-тивную деятельность студентов, направ-ленную на решение важных вопросов в различных сферах их жизни, но также, как способ приобретения лидерского опыта.

логия, практика: монография. СПб: Образование. 238 с.

6. Михайличенко, В. Е. (2015) Психология развития личности: монография. X.: 387 с.

$7 . \quad$ Романовский, А. Г. Михайличенко, В. Е. \& Грень, Л. Н. (2018) Педагогика лідерства. Х.: Стильиздат, 500 c.

8. Романовський, О. Г., Гура, Т. В. \& Книш, А. Є. (2017) Розвиток лідерського потенціалу в Центрі лідерства Національного технічного університету «Харківський політехнічний інститут». Теоретичний та методично-науковий часопис «Вищза освіта Украӥни». № 2 (додаток 1). С. 96-100.

9. Червона, Л. М. (2017) Студентське самоврядування як інструмент розвитку лідерського потенціалу університетів у контексті глобального лідерства. Теоретичний та методичнонауковий часопис «Вищза освіта України». № 2 (додаток 1). С. 149 - 154.

2. Beljakova, N. V. (2002) Social'nopsihologicheskie osobennosti projavlenija liderstva $v$ studencheskih gruppah. [Sociopsychological characteristics of the 
manifestation of leadership in student groups]: dis. kand. psihol. nauk: 19.00.05 M.197 p. [in Russian]

3.Hura, T. (2015) Liders'kyj potentsial iak vazhlyva skladova pedahohichnoi kul'tury vykladacha tekhnichnoho universytetu. [Leadership potential as an important component of the pedagogical culture of the teacher of the technical university]. Pedahohika formuvannia tvorchoi osobystosti u vyschij i zahal'noosvitnij shkolakh: zb. nauk. pr. Redkol.: T. I. Suschenko. Zaporizhzhia: KPU. Vyp. 44 (97). P. 418 428. [in Ukrainian]

4. Kirjushina, N. Ju. \& Tihonova, E.L. (2010) Sistema podgotovki liderov $v$ universitete. [University Leadership Training System]. Vestnik Nizhegorodskogo universiteta im. N. I. Lobachevskogo. P. 27 -33. [in Russian]

5. Makshanov, S. I. (1997) Psihologija treninga: teorija, metodologija, praktika: monografija. [Psychology of training: theory, methodology, practice: monograph]. SPb: Obrazovanie, 238 p. [in Russian]

6. Mihajlichenko, V. E. (2015) Psihologija razvitija lichnosti: monografija.
[Psychology of personality development: monograph]. Kh.: 387 p. [in Russian]

7. Romanovskyj, A. H. Mykhajlychenko, V. E. \& Hren', L. N. (2018) Pedahohyka liderstva. [Pedagogy of Leadership.]. Kh.: Styl'yzdat, 500 p. [in Ukrainian]

8. Romanovs'kyj, O. H., Hura, T. V. \& Knysh, A. Ye. (2017) Rozvytok liders'koho potentsialu $v$ Tsentri liderstva Natsional'noho tekhnichnoho universytetu «Kharkivs'kyj politekhnichnyj instytut». [Development of Leadership Capacity at the Center for Leadership at the National Technical University "Kharkiv Polytechnic Institute"]. Teoretychnyj ta metodychno-naukovyj chasopys «Vyscha osvita Ukrainy». № 2 $\begin{array}{llllll}\text { (dodatok } & 1 \text { ). } & \text { P. } & 96 & - & 100 .\end{array}$ [in Ukrainian]

9. Chervona, L. M. (2017) Students'ke samovriaduvannia iak instrument rozvytku liders'koho potentsialu universytetiv $u$ konteksti hlobal'noho liderstva. [Student SelfGovernment as a Tool for Developing Leadership Capacity of Universities in the context of Global Leadership]. Teoretychnyj ta metodychno-naukovyj chasopys «Vyscha osvita Ukrainy». № 2 (dodatok 1). P. 149 154. [in Ukrainian]

Стаття надійшла до редколегї 17.04.2019 